\title{
Covalent and Non-Covalent Binding Free Energy Calculations for Pep- tidomimetic Inhibitors of SARS-CoV-2 Main Protease
}

\author{
Ernest Awoonor-Williams* and Abd-Aziz A. Abu-Saleh* \\ Department of Chemistry, Memorial University of Newfoundland, St. John's, NL, A1B 3X9, Canada. \\ Absolute binding Free Energy, ONIOM (QM:MM), Peptidomimetic Inhibitors, SARS-CoV-2, Mpro, 3CL pro, Coronavirus, COVID-19
}

\begin{abstract}
COVID-19, the disease caused by the newly discovered coronavirus - SARS-CoV-2, has created global health, social, and economic crisis. At the time of writing (November 12, 2020), there are over 50 million confirmed cases and more than 1 million reported deaths due to COVID-19. Currently, there are no approved vaccines, and recently Veklury (remdesivir) was approved for the treatment of COVID19 requiring hospitalization. The main protease $\left(\mathrm{M}^{\mathrm{pro}}\right)$ of the virus is an attractive target for the development of effective antiviral therapeutics because it is required for proteolytic cleavage of viral polyproteins. Furthermore, the $\mathrm{M}^{\text {pro }}$ has no human homologues, so drugs designed to bind to this target directly have less risk for off-target reactivity. Recently, several high-resolution crystallographic structures of the $\mathrm{M}^{\text {pro }}$ in complex with inhibitors have been determined - to guide drug development and to spur efforts in structure-based drug design. One of the primary objectives of modern structure-based drug design is the accurate prediction of receptor-ligand binding affinities for rational drug design and discovery. Here, we perform rigorous alchemical absolute binding free energy calculations and QM/MM calculations to give insight into the total binding energy of two recently crystallized inhibitors of SARS-CoV-2 $\mathrm{M}^{\text {pro }}$, namely, $\mathrm{N} 3$ and $\alpha$-ketoamide $13 \mathrm{~b}$. The total binding energy consists of both covalent and non-covalent binding components since both compounds are covalent inhibitors of the $\mathrm{M}^{\text {pro }}$. Our results indicate that the covalent and non-covalent binding free energy contributions of both inhibitors to the $\mathrm{M}^{\mathrm{pro}}$ target differ significantly. The N3 inhibitor has more favourable non-covalent interactions, particularly hydrogen bonding, in the binding site of the $\mathrm{M}^{\text {pro }}$ than the $\alpha$-ketoamide inhibitor. But the Gibbs energy of reaction for the $\mathrm{M}^{\mathrm{pro}}-\alpha$-ketoamide covalent adduct is greater than the Gibbs reaction energy for the $\mathrm{M}^{\text {pro }}-\mathrm{N} 3$ covalent adduct. These differences in the covalent and non-covalent binding free energy contributions for both inhibitors could be a plausible explanation for their in vitro differences in antiviral activity. Our findings highlight the importance of both covalent and non-covalent binding free energy contributions to the absolute binding affinity of a covalent inhibitor towards its target.
\end{abstract}

\section{Introduction}

During the past two decades, a number of coronaviruses have emerged and caused outbreaks of global health concern. ${ }^{1}$ These include severe acute respiratory syndrome (SARS-CoV) in 2003 and Middle East respiratory syndrome (MERS-CoV) in 2012. In December 2019, a novel coronavirus (SARS-CoV-2) was identified in Wuhan, Hubei province in China. ${ }^{2,3}$ SARS-CoV-2 is responsible for the coronavirus disease of 2019 (COVID-19). These viruses mainly attack the lower respiratory system of humans and cause major symptoms such as fever, cough, sore throat, and pneumonia. ${ }^{4,5}$ Among respiratory viral infections, COVID-19 has the highest infection rate and spread. As of November 12, 2020, the World Health Organization (WHO) has confirmed over 50 million cases and more than 1 million deaths due to COVID-19 in 220 countries, areas or territories across the globe. ${ }^{6}$

SARS-CoV-2 has several key proteins such as the main protease $\left(\mathrm{M}^{\mathrm{pro}}\right)$; also known as $3 \mathrm{CL}^{\mathrm{pro}}$, papain-like protease ( $\left.\mathrm{PL}^{\mathrm{pro}}\right)$, RNAdependent RNA polymerase (RdRp), and spike glycoprotein. Both the $\mathrm{M}^{\text {pro }}$ and the $\mathrm{PL}^{\text {pro }}$ function in the cleavage of the viral polyprotein into individual functional units. ${ }^{7,8}$ The RdRp is responsible for replicating viral genome. ${ }^{9}$ The spike glycoprotein contains a receptor-binding domain that interacts with the peptidase domain of the human angiotensin-converting enzyme 2 (h-ACE2), therefore, mediates the fusion of the viral cell. ${ }^{10}$ It is well known that the $\mathrm{M}^{\mathrm{pro}}$ is essential for most of the cleavage processes during viral polyprotein processing. ${ }^{11-14}$ It is critical for the processing of 12 non-structural proteins (NSP4-Nsp16) including RNA replicase (NSP9), RdRp (NSP12), and helicase (NSP13). ${ }^{15-17}$ Moreover, the $\mathrm{M}^{\mathrm{pro}}$ is considered as an attractive drug target because no human proteases with analogous cleavage processes are known. Thus, designing potent inhibitors of the $\mathrm{M}^{\text {pro }}$ is a safe and effective approach to inhibiting the viral activity of SARS-CoV-2, with reduced risk of off-target adverse drug reactions.

Much effort has been spent on developing effective therapeutics in the fight against COVID-19. As of November 12, 2020, there are 48 candidate vaccines in clinical evaluation (phase I, II, and III) and about 164 candidate vaccines in preclinical evaluation as reported by the WHO.$^{18}$ Further, a plethora of drugs are being investigated for repurposing in the treatment of the disease. ${ }^{19}$ These drugs are also the subject of several clinical trials. Despite these efforts, to date, there are no approved vaccines for the treatment of COVID-19. For this reason, the pursuit of safe and effective therapeutics against the emerging SARS-CoV-2 virus is critically important and urgent in the global fight against COVID-19.

In silico approaches play a crucial role in accelerating the research and development processes of new potential pharmaceutical drugs. ${ }^{20}$ 
The $\mathrm{M}^{\text {pro }}$ structure-based drug design approach ${ }^{21,22}$ is one of the promising strategies for developing effective broad-spectrum antivirals against coronaviruses because inhibiting $\mathrm{M}^{\text {pro }}$ blocks a key piece of the cell-replication machinery of the virus. Molecular docking, structure-activity relationship studies, and molecular dynamics (MD) simulations have been implemented for the discovery of potential inhibitors of the viral $\mathrm{M}^{\text {pro }}$. For instance, computational studies have explored drug repurposing or repositioning of a wide array of chemical compounds, including FDA approved drugs, ${ }^{16,23}$ antiviral compounds, ${ }^{24-27}$ protease inhibitors, ${ }^{28}$ antiviral phytochemicals, ${ }^{29}$ and natural products from medicinal plants, ${ }^{28,30,31}$ — with the sole aim of disrupting the viral function of the $\mathrm{M}^{\mathrm{pro}}$.

Recently, a number of high-resolution inhibitor-bound structures of the $\mathrm{M}^{\mathrm{pro}}$ have been determined. ${ }^{32-35}$ The availability of these structures have enabled structure-based modeling approaches in an effort to understand key inhibitor-receptor interactions, conformational dynamics, and structural stability of the binding domain of the $\mathrm{M}^{\text {pro }} \cdot{ }^{36-44}$ A principal goal of computational drug design is the ability to accurately and reliably predict the binding mode, selectivity, and affinity of a drug candidate towards a target. Alchemical absolute binding free energy (ABFE) calculations are suitable in this regard and provide a theoretically rigorous way of computing ligand binding energies of disease targets. ${ }^{45} \mathrm{ABFE}$ calculations have been shown to provide accurate estimates of the binding affinity and selectivity of drug-like molecules to therapeutically relevant enzyme targets. ${ }^{46-}$ ${ }^{51}$ We employ this approach to compute the ligand binding energies of two recently crystallized peptidomimetic inhibitors of SARSCoV-2 $\mathrm{M}^{\text {pro }}$, namely, $\mathrm{N}^{33}$ and $\alpha$-ketoamide $13 \mathrm{~b}^{34}$ (Figure 1). Both inhibitors are targeted covalent inhibitors of SARS-CoV-2 $\mathrm{M}^{\text {pro }}$. They initially bind to the $\mathrm{M}^{\text {pro }}$ by forming a non-covalent proteinligand complex, after which a covalent bond is formed between the electrophilic reactive group of the inhibitor (commonly referred to as "warhead") and cysteine-145 ("Cys145") of the $\mathrm{M}^{\text {pro }}$. Given that these inhibitors are covalent modifiers, modeling their binding steps would require calculation of both the non-covalent and covalent binding energy contributions. ${ }^{51-53}$

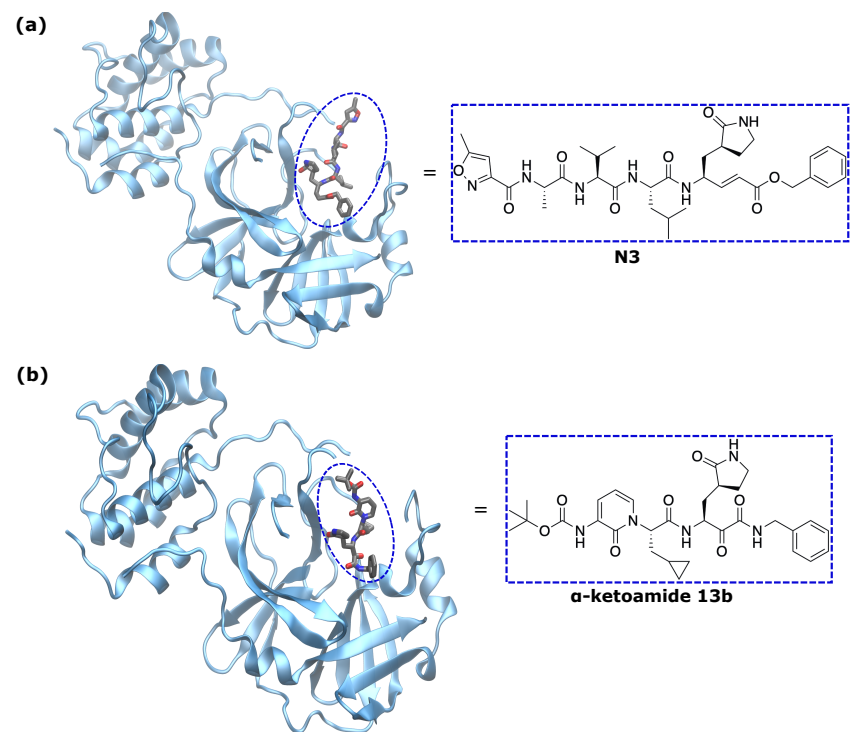

Figure 1. Structure of SARS-CoV-2 $\mathrm{M}^{\text {pro }}$ in complex with peptidomimetic inhibitors $\mathrm{N} 3(\mathbf{a})$, and $\alpha$-ketoamide $13 \mathrm{~b}(\mathbf{b})$. The chemical structures of the inhibitors are highlighted. Crystal structures of the $\mathrm{M}^{\text {pro }}$ in complex with $\mathrm{N} 3$ and $\alpha$-ketoamide $13 \mathrm{~b}$ inhibitors were derived from PDB accession codes 6LU7 and 6Y2G, respectively.
Here, we perform alchemical ABFE calculations to predict the binding free energy of $\mathrm{N} 3$ and $a$-ketoamide 13b (" $\alpha$-ketoamide") to SARS-CoV-2 $\mathrm{M}^{\text {pro }}$. This approach computes the absolute non-covalent binding energy of the inhibitors to the $\mathrm{M}^{\text {pro }}$ target and includes protein dynamics, conformational and orientational entropy of the inhibitors, in addition to non-covalent binding interaction energies. The covalent binding energy contribution of the chemical reaction was estimated using quantum mechanics/molecular mechanics (QM/MM) calculations within the $\mathrm{ONIOM}^{54}$ framework. We also computed the conformational Gibbs energy of the inhibitors upon binding to the $\mathrm{M}^{\text {pro }}$ using umbrella sampling/replica-exchange molecular dynamics method. To determine the preferred protonation states of key active site residues in the binding pocket of the protein, we performed constant-pH molecular dynamics simulations on the model systems, prior to running the binding free energy calculations. This combined computational approach provides insight into understanding key molecular interactions and free energy contributions that drive the binding processes of the inhibitors to SARS$\mathrm{CoV}-2 \mathrm{M}^{\mathrm{pro}}$. The information from this work will guide lead optimization studies and help with ongoing drug design efforts towards the development of effective antivirals to combat COVID-19.

\section{Theory and Methods}

System Preparation: The initial structures of the peptide-like inhibitors (N3 and $\alpha$-ketoamide) complexed with the SARS-CoV-2 $\mathrm{M}^{\text {pro }}$ were derived from $\mathrm{PDB}$ entries $6 \mathrm{LU}^{33}$ and $6 \mathrm{Y} 2 \mathrm{G},{ }^{34}$ respectively. Model systems of the protein-ligand complexes of these structures were prepared in explicit solvent. All crystallographically resolved water molecules were retained in the model system. The parameters for the protein and ligand model structures were obtained from the CHARMM36 protein force field ${ }^{55}$ and the CHARMM General Force Field (CGENFF), ${ }^{56}$ respectively. The TIP3P water model ${ }^{57}$ was chosen to describe water molecules in a cubic box. Molecular dynamics simulations were performed on the model system using NAMD 2.13. ${ }^{58}$ Simulations were performed under periodic boundary conditions at a constant temperature of $298.15 \mathrm{~K}$ and pressure of 1 atm using Langevin dynamics and Langevin piston method, respectively. A timestep of 2 fs and a Langevin damping coefficient of 1 ps was used for the MD simulations. The Particle Mesh Ewald (PME) method ${ }^{59,60}$ was used to describe long-range interactions and a cut-off distance of $12 \AA$ was used for the Lennard-Jones interactions. Covalent bonds involving hydrogen atoms were constrained using the SHAKE algorithm. ${ }^{61}$ Energy minimization calculations were performed on the protein-ligand model complexes, after which a series of equilibration runs lasting $50 \mathrm{~ns}$ were performed on the model structures first with restraints on the $\alpha$-carbon of the protein backbone, and then without restraints on the model system.

Constant-pH Molecular Dynamics Simulations: Following equilibration of the protein-ligand model complexes, constant- $\mathrm{pH}$ molecular dynamics simulations were performed to determine the protonation states of key amino acid residues, particularly, Cys 145 and His 41 which constitute the catalytic dyad of the SARS-CoV-2 $\mathrm{M}^{\text {pro }}$. This was done in order to account for the variation in protonation states of titratable active site residues relevant for the absolute binding free energy calculations, as well as $\mathrm{pH}$-induced conformational changes and inter-residue coupling effects within the model system. Recently, constant-pH molecular dynamics simulations was used to investigate the protonation states and proton-coupled conformational dynamics of catalytic residues in coronavirus $\mathrm{PL}^{\text {pro's }}{ }^{62}$ 
The constant-pH MD simulations were performed using the hybrid non-equilibrium molecular dynamics/Monte Carlo method ${ }^{63}$ implemented in NAMD 2.13. ${ }^{58}$ Simulations were performed in explicit solvent for the monomeric apo form (i.e., no inhibitor bound, PDB ID: 6M03) and holo forms (i.e., inhibitor bound, PDB IDs: 6LU7 and $6 \mathrm{Y} 2 \mathrm{G}$ ) of the coronavirus $\mathrm{M}^{\text {pro }}$ model structures. The CHARMM36 protein force field was used for generating structural models for the apo and holo forms of the model system. Our previous studies have shown that for titratable residue $\mathrm{pK}_{\mathrm{a}}$ calculations, particularly for cysteines, the CHARMM36 protein force field gives accurate cysteine $\mathrm{pK}_{\mathrm{a}} \mathrm{s}^{64,65}$ and correctly represents the hydration structure of model thiolates. ${ }^{66}$ All ionizable residue side chains in the model system were allowed to titrate. The equilibrated model system structures were used as the starting point for the constant-pH MD simulations. The constant- $\mathrm{pH}$ simulations were initially minimized for 200 steps within the constant-pH molecular dynamics framework, and this was followed by a $100 \mathrm{~ns}$ run for each $\mathrm{pH}$ window within intervals of 1.0-14.0. All simulations attempted protonation state moves of $10 \mathrm{ps}$, with switching times of $15 \mathrm{ps}$. The titration curve was plotted from the simulation output by fitting the deprotonated fraction $\left(f_{\text {deprot }}\right)$ and $\mathrm{pH}$ for each replica window to the Hill equation, Eqn. (1), where $n$ is the Hill coefficient.

$$
f_{\text {deprot }}=\frac{1}{1+10^{\mathrm{n}\left(\mathrm{pK}_{\mathrm{a}}-\mathrm{pH}\right)}}
$$

Absolute Binding Free Energy Calculation: The absolute binding free energy of N3 and $\alpha$-ketoamide inhibitors were calculated using alchemical free energy calculations following the protocol reported by Aldeghi et al. ${ }^{49}$ This approach follows a nonphysical thermodynamic cycle depicted in Figure 2 to determine the binding free energy of a ligand to a protein target.

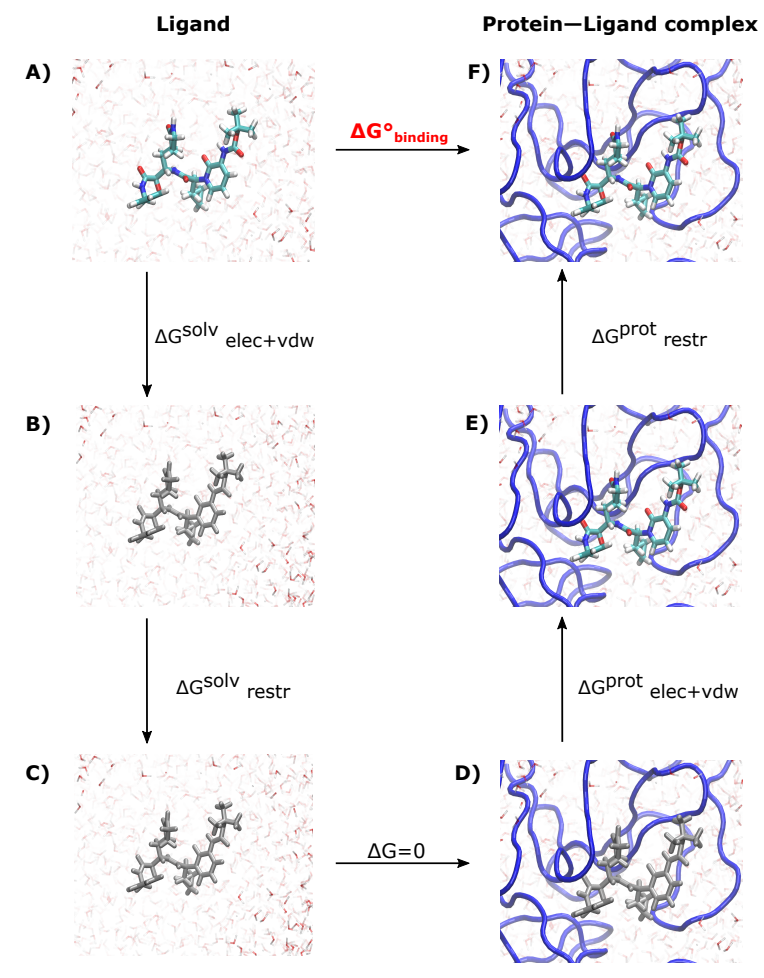

Figure 2. Scheme depicting the alchemical thermodynamic cycle used for computing the absolute binding free energies of the peptidomimetic inhibitors to SARS-CoV-2 M ${ }^{\text {pro }}$, following the protocol of Aldeghi et al. ${ }^{49}$ $\Delta G_{\text {elec }+v d w}^{\text {solv }}$ represent the electrostatic and van der Waals interaction energy following decoupling of the fully interacting ligand in solution (A) into a non-interacting ligand (B). $\Delta G_{\text {restr }}^{\text {solv }}$ represents the free energy cost of imposing restraints on the non-interacting ligand in solution (C); state $\mathrm{C}$ (non-interacting ligand in solution) and state $\mathbf{D}$ (non-interacting ligand in protein) are equivalent to each other. $\Delta G_{\text {elec }+v d w}^{\text {prot }}$ represent the electrostatic and van der Waals interaction energy of the fully interacting but restrained ligand in the protein $(\mathbf{E}) . \Delta G_{\text {restr }}^{\text {prot }}$ represent the free energy cost associated with removal of restraints on the ligand to yield a fully interacting ligand in the protein binding site $(\mathbf{F})$.

The computed binding free energy, which corresponds to the absolute non-covalent binding energy of the ligand to the target, is computed by following a series of alchemical transformations that characterize the binding event, Figure 2 . The resulting ligand binding energy is simply derived from the sum of the multiple steps where the ligand is desolvated from solution and then introduced into the binding site of the target protein. The calculations are performed for the ligand in bulk solution (i.e., unbound state) and in the protein binding site (i.e., bound state), and correspond to the forces and intermolecular interactions of the ligand accompanying the binding process.

The simulations were performed using the GROMACS molecular dynamics software package (version 2019.4). ${ }^{67}$ The AMBER99SB$\mathrm{ILDNP}^{68}$ and $\mathrm{GAFF}^{69}$ force fields were used to generate parameters for the protein and ligands, respectively. For the ABFE calculations, two sets of simulations were performed; where the ligand was decoupled from bulk solution (i.e., unbound state) and from the complex (i.e., bound state). The van der Waals and coulombic interactions of the ligand in both bulk and complex environments were slowly decoupled during the simulation via a linear alchemical pathway with $\Delta \lambda=0.05$ and $\Delta \lambda=0.1$, respectively. A total of $31 \lambda$ windows were employed for decoupling the ligand in bulk solution and $42 \lambda$ windows were employed for the complex simulation (see Supporting Information). For each $\lambda$ window, energy minimization, NVT and NPT equilibrations, and production runs were performed. The energy minimization was carried out using the steepest descent algorithm for a maximum of 100,000 steps. This was followed by a $1 \mathrm{~ns}$ equilibration under canonical ensemble conditions (NVT) with harmonic position restraints applied to ligand heavy atoms with a force constant of $1000 \mathrm{kcal} \mathrm{mol}^{-1} \mathrm{~nm}^{-2}$. Simulation temperature was coupled using Langevin dynamics ${ }^{70}$ with reference temperature set to $298.15 \mathrm{~K}$. Following the NVT equilibration runs, a 1 ns position restrained simulation under isothermal-isobaric (NPT) ensemble conditions was performed using the Berendsen algorithm. ${ }^{71}$ Subsequently, a 12 ns unrestrained production run was performed using Hamiltonian replica exchange (HREX) for each $\lambda$ window under NPT conditions using the Parrinello-Rahman pressure coupling scheme. ${ }^{72}$ For the HREX simulations, 1 million global replica exchange swaps were attempted every 1000 time steps. The average acceptance ratio between replicas ranged from 0.2 to 0.3 . The simulations were performed in triplicate for both the ligand in bulk solution and in the protein, yielding an aggregate total of $\simeq 1.1 \mu$ s and $\simeq 1.5 \mu$ s simulation time for the bulk and protein simulations, respectively. The results were analyzed using the alchemical_analysis.py python tool. ${ }^{73}$ The reported free energies are the averages of the triplicate runs, and were calculated using multistate Bennet acceptance ratio (MBAR),$^{74}$ after discarding the first $2 \mathrm{~ns}$ of each window as equilibration. The timestep used for all simulations was $2 \mathrm{fs}$ and the PME algorithm was used to treat long-range electrostatic 
interactions with a cut-off of $12 \AA$. The LINCS constraint algorithm was used to constrain $\mathrm{H}$-bonds.

The relative position and orientation of the bound ligand in the complex was described using six internal coordinates; one distance, two angles, and three dihedrals (see Supporting Information). These restraints help to keep the ligand in its bound pose in the binding pocket of the enzyme during the decoupling steps of the free energy calculations. The force constant used for the distance restraint was $1000 \mathrm{kcal} \mathrm{mol}^{-1} \mathrm{~nm}^{-2}$, and a force constant of $10 \mathrm{kcal} \mathrm{mol}^{-1} \mathrm{rad}^{-2}$ was used for both angle and dihedral harmonic potentials. For the simulations involving the decoupling of the ligand from bulk solution, the restraint energy term $\left(\Delta G_{\text {restr. }}^{\text {solv }}\right)$ is computed analytically using the method proposed by Boresch et al. ${ }^{75}$ The decoupling simulations of the ligand in complex with the protein $\left(\Delta G_{\text {elec }+v d w+r e s t r .}^{\text {prot }}\right)$ on the other hand, is evaluated numerically from the free energy calculations. The resulting absolute binding free energy of ligand to enzyme target, given by the expression in Eqn. (2), simply represents the interaction energy following the dissociation of the ligand from bulk solution and its association in the binding site of the protein.

$$
\begin{gathered}
\Delta G_{\text {binding }}^{o}=\Delta G_{\text {elec }+v d w+r e s t r}^{\text {prot }}+\Delta G_{\text {elec }+v d w}^{\text {solv }} \\
+\Delta G_{\text {restr_on }}^{\text {solv }}
\end{gathered}
$$

Calculation of Ligand Conformational Degrees of Freedom: Upon ligand binding to target protein, there is a free energy cost associated with the loss of conformational degrees of freedom when the ligand adopts a particular conformation in the binding pocket of the target protein. The conformational free energy term accompanying ligand binding to the target site (i.e., $\Delta G_{\text {conf }}$ ) was computed using umbrella sampling/replica-exchange molecular dynamics simulations. The simulations were performed for the ligand in bulk solution $\left(\Delta G_{\text {conf }, \text { solv }}\right)$ and in the protein binding site $\left(\Delta G_{\text {conf,site }}\right)$, and consisted of 12 replicas centered on RMSD offsets increasing from 0.0-5.5 in increments of $0.50 \AA$. The force constant for the RMSD restraints was $50 \mathrm{kcal} \mathrm{mol}^{-1} \AA^{-2}$. The simulation length for each replica window was $20 \mathrm{~ns}$, resulting in an aggregate simulation time of $240 \mathrm{~ns}$ for a single run. For each system, three independent runs were performed, yielding a cumulative total of $720 \mathrm{~ns}$ simulation time. Weighted histogram analysis method ${ }^{76}$ (WHAM) was used to compute the potential of mean force (PMF) as a function of the rootmean square deviation (RMSD) relative to a reference bound state conformation of the ligand. The average conformation of the boundstate ligand from the equilibration run was used as the reference structure.

ONIOM(QM:MM) Methodology: The QM/MM calculations performed in our study employed the $\mathrm{ONIOM}^{54}$ approach as implemented in Gaussian 16. ${ }^{77}$ The final coordinates of the binding free energy calculations were used to generate the ONIOM (QM:MM) models. In these models, explicit solvent water molecules and ions were removed. The system was partitioned into two layers: (1) High-level QM region, which consists of the thiol side chain of Cys 145 of the $\mathrm{M}^{\text {pro }}$ with a molecular scaffold of the inhibitor that includes the electrophilic warhead, Figure 3; and (2) Low-level molecular mechanical region, which includes all the remaining residues of the $\mathrm{M}^{\text {pro }}$. The high-level QM region was treated using the M06-2X functional with the def2-TZVP basis set. The M06-2X functional has been shown to perform very well for thermochemistry of main group elements ${ }^{78}$ and yields accurate reaction energies for covalent modification of thiols. ${ }^{53}$ The Amber molecular mechanics force field was used to treat the low-level MM region, with parameters and charges the same as those used for the absolute binding free energy calculations. The chemical bonds at the QM/MM boundary interface were capped with hydrogen link atoms.

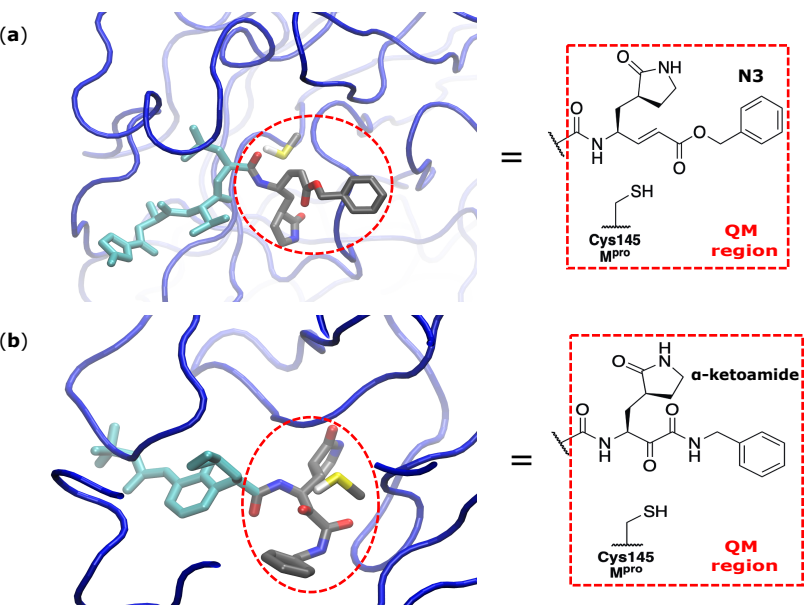

Figure 3. High-level QM region defined in our ONIOM (QM:MM) model to estimate the covalent bonding reaction energy of the inhibitors following chemical addition to Cys 145 of the $\mathrm{M}^{\text {pro }}$.

For the $\mathrm{M}^{\text {pro }}-\mathrm{N} 3$ ONIOM(QM:MM) model, the high-level layer consisted of 47 atoms and the low-level layer consisted of 4732 atoms. Similarly, for the $\mathrm{M}^{\text {pro }}-\alpha$-ketoamide $\operatorname{ONIOM(QM:MM)~}$ model, the high-level layer consisted of 46 atoms and the low-level layer consisted of 4667 atoms. All chemical structures of the model systems were optimized using the ONIOM (M06-2X/def2TZVP:AMBER) method within a mechanical embedding formalism. The optimized structures on the free energy surfaces (FESs) were validated by analysis of the corresponding Hessian matrices. The covalent and non-covalent $\mathrm{M}^{\mathrm{pro}}$-inhibitor complexes associated with the transition states were analyzed using intrinsic reaction coordinate calculations. ${ }^{79,80}$ It should be noted that the transition states were based on the bimolecular concerted reaction mechanism between Cys 145 of the $\mathrm{M}^{\mathrm{pro}}$ and the electrophilic warhead of the inhibitors. Single point energy calculations were also performed on the optimized structures using ONIOM (M06-2X/def2TZVP:AMBER) method within an electrostatic embedding formalism.

\section{Results and Discussion}

The binding free energies of two recently crystallized peptidomimetic inhibitors (i.e., N3 and $\alpha$-ketoamide) of SARS-CoV-2 $\mathrm{M}^{\text {pro }}$ were computed using rigorous alchemical absolute binding free energy calculations and hybrid QM/MM methods. Given that these inhibitors are covalent modifiers of the $\mathrm{M}^{\text {pro }}$ target, their binding modes consists of both covalent and non-covalent binding steps. As a result, the total binding free energy of the inhibitors involved the calculation of both covalent and non-covalent binding free energies. The non-covalent binding free energy of the inhibitors to the $\mathrm{M}^{\text {pro }}$ target was calculated using alchemical ABFE calculations, while the covalent binding free energy was estimated using the ONIOM $\mathrm{QM} / \mathrm{MM}$ method. 


\section{$\mathrm{pK}_{a}$ Calculations of His41 and Cys145 residues of the $\mathrm{M}^{\text {pro }}$}

Prior to running the binding free energy calculations, we performed constant-pH MD simulations on the model systems to determine the preferred protonation states of key binding site residues in the target $\mathrm{M}^{\text {pro }}$, particularly the catalytic His41/Cys145 dyad. Constant$\mathrm{pH} \mathrm{MD}$ allows multiple protonation states to be modeled simultaneously. Given that changes in the protonation states of amino acid residues can induce protein conformational dynamics, we performed constant-pH MD simulations to explore variations in residue protonation states and the dynamics of ionization equilibria in the model systems. The constant-pH MD simulations were performed for both apo and holo forms of the $\mathrm{M}^{\mathrm{pro}}$ model structures. Figures 4 and 5 depict the percentage of time that Cys145 and His 41 are deprotonated as a function of $\mathrm{pH}$ in the apo and holo forms of the $\mathrm{M}^{\text {pro }}$. For apo form of the $\mathrm{M}^{\mathrm{pro}}$ (PDB ID: 6M03), the $\mathrm{pK}_{\mathrm{a}}$ 's of His41 and Cys145 were predicted to be 5.8 and 9.4, respectively (Figure 4). This suggests that in the ligand-free form of the $M^{\text {pro }}$, the preferred protonation state of both Cys145 and His41 is uncharged; where the thiol group of Cys 145 is protonated and the imidazole functional group of His 41 is neutral. Similarly, the $\mathrm{pK}_{\mathrm{a}}$ 's of His 41 and Cys 145 in both $\mathrm{N} 3$ and $\alpha$-ketoamide bound complexes of the $\mathrm{M}^{\text {pro }}$ also suggest that both residues are in their neutral form (Figure 5). This result is in agreement with recent multiscale simulation studies on the proteolysis mechanism of SARS-CoV-2 $\mathrm{M}^{\text {pro }} .{ }^{81,82}$ Additionally, experimental studies performed on the catalytic mechanism of SARS-CoV M ${ }^{\text {pro }}$ concluded that Cys 145 and His 41 are in their neutral form. ${ }^{83}$ Both SARS-CoV and SARS-CoV-2 share very high structural and sequence identity (96\%) for their $\mathrm{M}^{\mathrm{pro}}{ }^{\mathrm{s}}{ }^{84}$ Therefore, in our binding free energy simulations both Cys145 and His41 were treated as neutral uncharged residues. In addition, the tautomeric states of His41-His164 pair for the $\alpha$-ketoamide and N3-bound $\mathrm{M}^{\mathrm{pro}}$ structures were chosen based on molecular dynamics simulation results reported by Gumbart and coworkers ${ }^{41}$ on the structural stability of the $\mathrm{M}^{\text {pro }}$ as a function of protonation state assignment.

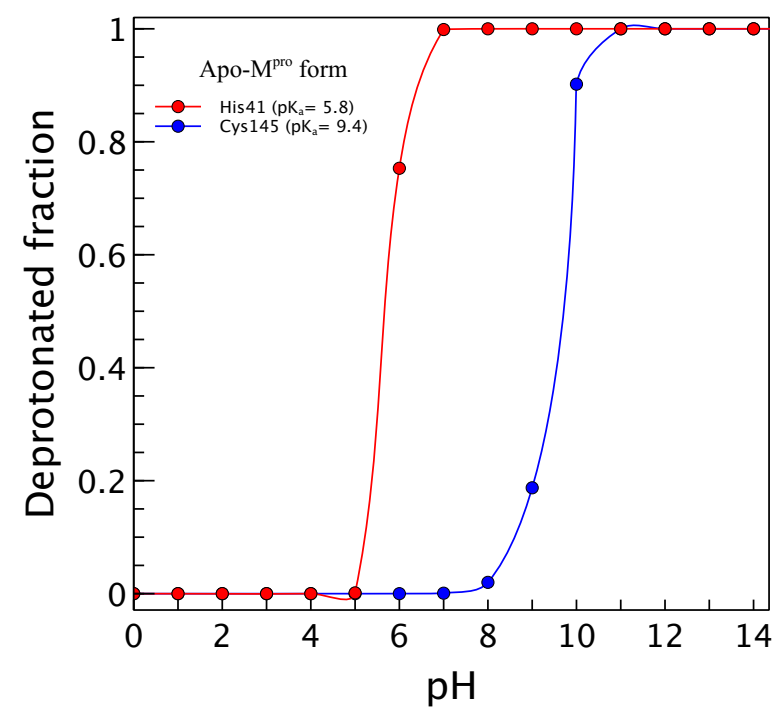

Figure 4. Titration curves of His41 and Cys 145 in the apo form of SARS-CoV-2 Mpro (PDB ID: 6M03). The predicted $\mathrm{pK}_{\mathrm{a}}$ 's of His41 and Cys 145 of the $\mathrm{M}^{\text {pro }}$ are 5.8 and 9.4, respectively.
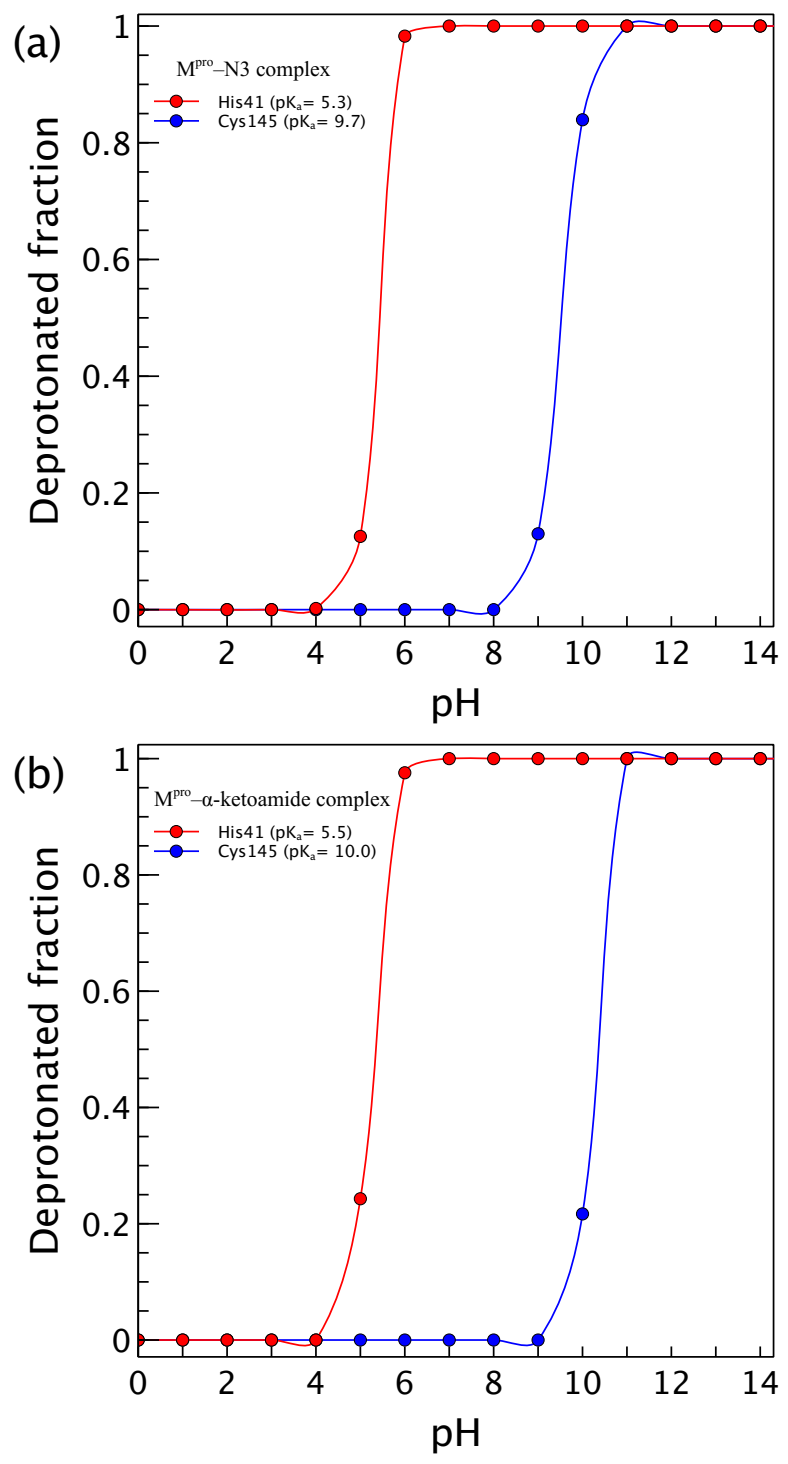

Figure 5. Titration curves of His 41 and Cys 145 in the holo form of SARS-CoV-2 $\mathrm{M}^{\text {pro }}$. (a) For the N3 bound complex of the $\mathrm{M}^{\text {pro }}$ (PDB ID: 6LU7), the predicted $\mathrm{pK}_{\mathrm{a}}$ 's of His41 and Cys145 are 5.3 and 9.7, respectively. (b) For the $\boldsymbol{\alpha}$-ketoamide bound complex of the $\mathrm{M}^{\text {pro }}$ (PDB ID: $6 \mathrm{Y} 2 \mathrm{G}$ ), the predicted $\mathrm{pK}_{\mathrm{a}}$ 's of His41 and Cys145 are 5.5 and 10.0, respectively.

\section{Non-covalent Binding Free Energy Contribution}

Using the nonphysical thermodynamic cycle depicted in Figure 2, the binding free energies of $\mathrm{N} 3$ and $\alpha$-ketoamide to SARS-CoV-2 $\mathrm{M}^{\text {pro }}$ were predicted to be $-6.3 \pm 0.6 \mathrm{kcal} \mathrm{mol}^{-1}$ and $-2.5 \pm 0.2 \mathrm{kcal}$ $\mathrm{mol}^{-1}$, respectively. These values represent the non-covalent interaction energies between the inhibitors and the $\mathrm{M}^{\mathrm{pro}}$ and provide a good estimate of their binding affinities. In particular, the binding free energy results of $\mathrm{N} 3$ to SARS-CoV-2 $\mathrm{M}^{\text {pro }}$ is in good agreement with experimental binding affinity measurements of N3 binding to SARS$\mathrm{CoV} \mathrm{M}^{\text {pro }}$. The experimental inhibitory constant $\left(\mathrm{K}_{\mathrm{i}}\right)$ of $\mathrm{N} 3$ to SARS-CoV $\mathrm{M}^{\text {pro }}$ is $9.0 \mu \mathrm{m},{ }^{85}$ corresponding to a $\Delta \mathrm{G}^{\circ}$ expt. value of -6.9 $\mathrm{kcal} \mathrm{mol}^{-1}$. Both SARS-CoV and SARS-CoV-2 $\mathrm{M}^{\text {pro's }}$ are highly similar-sharing $\sim 96 \%$ sequence identity - so we can expect that the 
binding affinity of $\mathrm{N} 3$ is similar for both targets. This makes us confident in our predicted binding free energy results.

The computed binding energy suggests that N3 inhibitor enjoys slightly more favourable non-covalent interactions in the binding site of the $\mathrm{M}^{\mathrm{pro}}$ than the a-ketoamide inhibitor. Analysis of the ligand interaction diagram of the equilibrated protein-ligand complexes of both inhibitors with the $\mathrm{M}^{\text {pro }}$ (Figure 6) indicates that N3 inhibitor indeed forms more hydrogen bonding interactions with key amino acid residues in the binding site of the $\mathrm{M}^{\text {pro }}$ than the $\alpha$-ketoamide inhibitor. Figure 6(a) shows that N3 interacts with residues Thr190, Gln189, Glu166, His163, His164, and Gly143 of the $\mathrm{M}^{\text {pro }}$ through hydrogen bonding. The $\alpha$-ketoamide inhibitor on the other hand, interacts through hydrogen bonding with residues Glu166, Cys145, His41, and His 164 of the $\mathrm{M}^{\mathrm{pro}}$, Figure 6(b). Both inhibitors form hydrogen bonding interactions with residues Glu166 and His164. This result indicates that hydrogen bonding interactions play a significant role in the non-covalent binding interaction energy of $\mathrm{N} 3$ and $\alpha$-ketoamide inhibitors to the $\mathrm{M}^{\text {pro }}$. In addition, the relatively large size of $\mathrm{N} 3$ in comparison with the $\alpha$-ketoamide inhibitor could also contribute to enhancing the non-covalent binding interactions since this could lead to more dispersive interactions in the binding site of the target — favouring ligand binding.

(a)

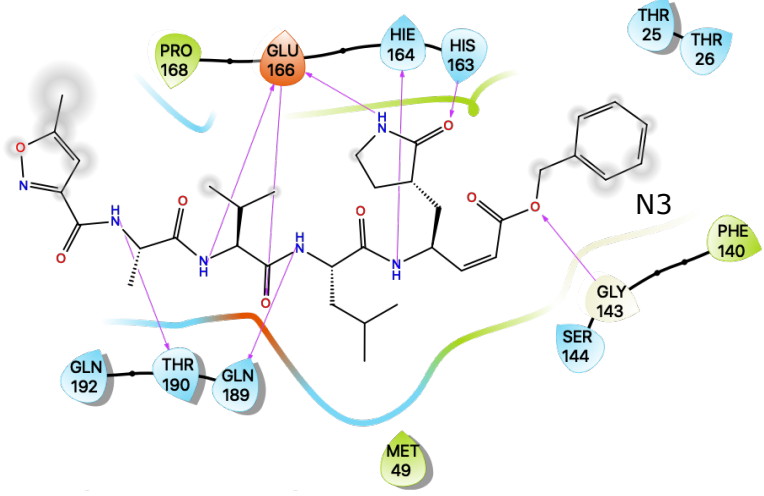

(b)

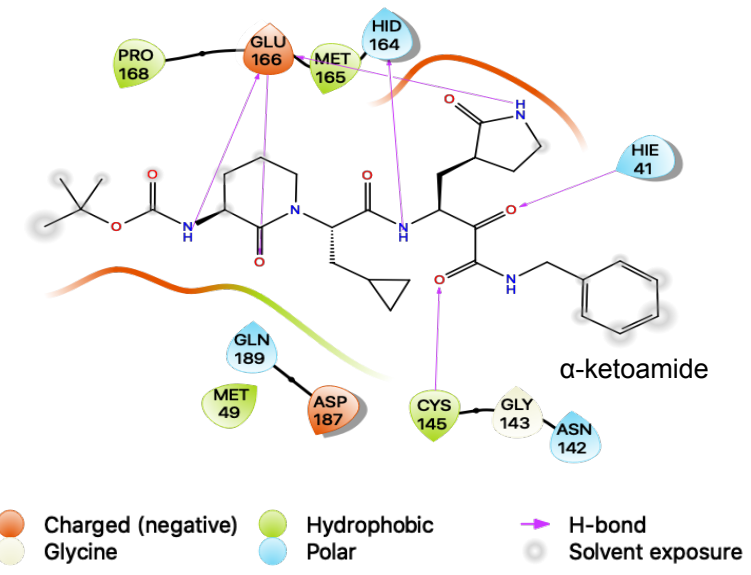

Figure 6. 2D Ligand interaction map showing active site residues of the $M^{\text {pro }}$ that engage in hydrogen bonding interactions with $\mathrm{N} 3(\mathbf{a})$ and $\boldsymbol{\alpha}$ ketoamide (b) inhibitors. Only residues that are within $2.5 \AA$ of the inhibitors are shown. N3 and $\boldsymbol{\alpha}$-ketoamide inhibitors in complex with the $\mathrm{M}^{\mathrm{pro}}$ were derived from $\mathrm{PDB}$ accession codes $6 \mathrm{LU} 7$ and $6 \mathrm{Y} 2 \mathrm{G}$, respectively.

\section{Covalent Binding Free Energy Contribution}

Both N3 and $\alpha$-ketoamide are covalent inhibitors of the $\mathrm{M}^{\text {pro }}, 3,34$ as such their total binding energy consists of both non-covalent and covalent binding energy terms. The covalent binding energy results from the covalent adduct formation between Cys 145 of the $\mathrm{M}^{\mathrm{pro}}$ and the electrophilic warhead of the inhibitors (Scheme 1). To calculate the binding free energy associated with the covalent bond formation, we performed ONIOM QM/MM calculations to estimate the relative Gibbs energy difference between the non-covalent inhibitorbound complex and the final covalent adduct.

Scheme 1: Reaction scheme depicting covalent bond formation between Cys 145 residue of the $M^{\text {pro }}$ with the electrophilic warheads of N3 (a), and a-ketoamide (b). Only sections of the protein and ligand included in the $Q M$ region of our $Q M / M M$ model are shown. (a)

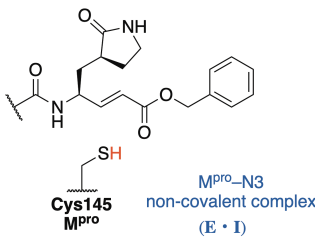

(b)

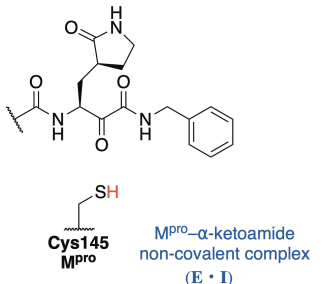

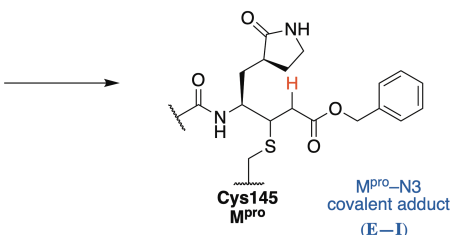

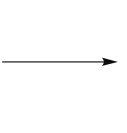

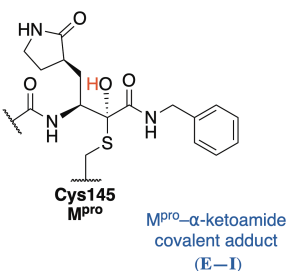

From our ONIOM (QM:MM) calculations, the free energy difference between the non-covalent complex and the covalently-bound $\mathrm{M}^{\text {pro }}-\mathrm{N} 3$ adduct is $-3.5 \mathrm{kcal} \mathrm{mol}^{-1}$. For the $\alpha$-ketoamide inhibitor complexes, the computed free energy difference between the noncovalent and covalent adduct is $-7.9 \mathrm{kcal} \mathrm{mol}^{-1}$. This result indicates that the free energy leading to the formation of the inhibitor-bound covalent complexes represents an exergonic process. In addition, the results suggest that the covalent binding energy of the $\alpha$-ketoamide inhibitor to the $\mathrm{M}^{\text {pro }}$ is more than two times the covalent energy contribution of $\mathrm{N} 3$ to the $\mathrm{M}^{\text {pro }}$. Overall, our binding free energy results indicate that $\alpha$-ketoamide is a more potent inhibitor of the $\mathrm{M}^{\text {pro }}$ than $\mathrm{N} 3$, based on the total binding free energy (Table 1). This result is corroborated by experimental findings which report that $a$-ketoamide inhibitor displays slightly better in vitro antiviral activity than N3 in SARS-CoV-2 cell-based assays ( $4-5 \mu \mathrm{M}$ for $\alpha$-ketoamide vs. $\sim 16.8 \mu \mathrm{M}$ for N3) ${ }^{33,34}$ This indicates that both covalent and noncovalent binding free energy terms are important in the total binding affinity of a covalent inhibitor towards its target.

Table 1. Summary of Binding Free Energy Results for the $\mathbf{M}^{\text {pro }}$ Inhibitors Studied in this Work.

\begin{tabular}{|c|c|c|c|}
\hline Inhibitor & $\begin{array}{c}\Delta \boldsymbol{G}_{\text {non-covalent. }} \\
\left(\mathrm{kcal} \mathrm{mol}^{-1}\right)\end{array}$ & $\begin{array}{c}\Delta \boldsymbol{G}_{\text {covalent }} \\
\left(\mathrm{kcal} \mathrm{mol}^{-1}\right)\end{array}$ & $\begin{array}{c}\left.\Delta \boldsymbol{G}_{\text {total }}\right) \\
\left(\mathrm{kcal} \mathrm{mol}^{-1}\right)\end{array}$ \\
\hline $\mathrm{N} 3$ & $-6.3 \pm 0.6$ & -3.5 & $-9.8 \pm 0.6$ \\
\hline$\alpha$-ketoamide & $-2.5 \pm 0.2$ & -7.9 & $-10.4 \pm 0.2$ \\
\hline
\end{tabular}


Conformational Energies. The conformational degrees of freedom accompanying protein-ligand binding is a significant component of the binding free energy. Typically, upon ligand binding to a target protein, there is a free energy cost associated with the loss of conformational freedom as a result of the ligand taking up a specific conformation in the binding site of the protein. This conformational free energy cost can be evaluated by calculating the PMF (in bulk solvent and in the protein binding site) as a function of the RMSD of the ligand relative to a reference bound state conformation. ${ }^{86}$ Figure 7 shows the PMF of the inhibitors in bulk solution and in the protein binding site of the $\mathrm{M}^{\mathrm{pro}}$. From this figure, the PMF of the inhibitors in bulk solution is generally broader than in the binding pocket of the protein. This suggests that a range of stable conformational states are accessible to the inhibitors in bulk solution than in the protein binding site. It is also evident from this figure that there is a significant difference between the low energy conformational states of the inhibitor in the protein-binding site and in bulk solution, Figure 8.
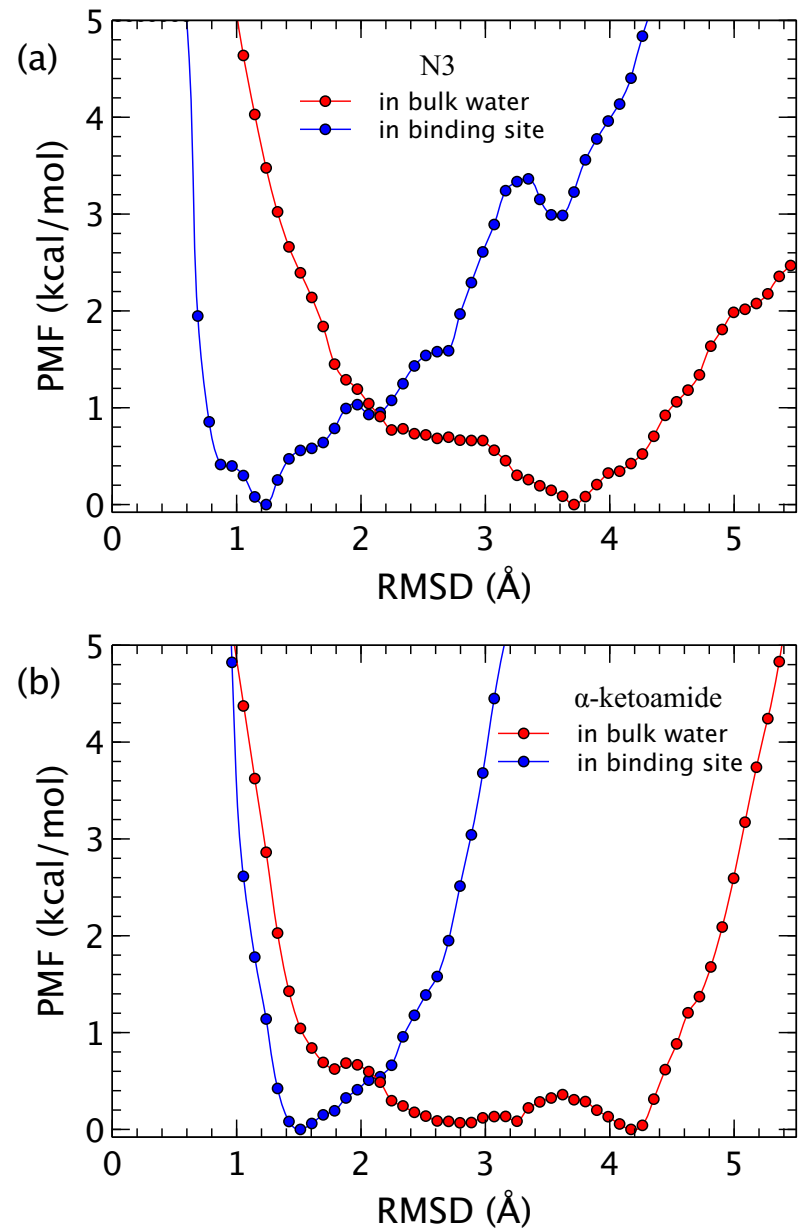

Figure 7. Potential of mean force (PMF) for the peptidomimetic inhibitors N3 (a), and $a$-ketoamide (b) as a function of the root-mean-square deviation (RMSD) relative to an average reference bound state conformation in bulk solution and in the $\mathrm{M}^{\text {pro }}$ binding site.
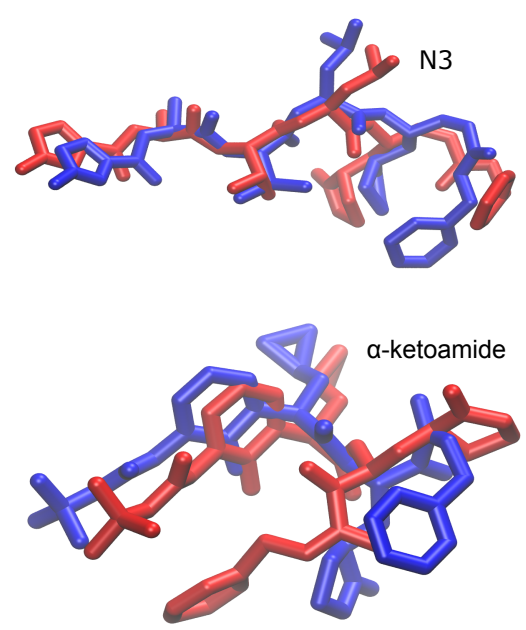

Figure 8. Low energy conformation states of the inhibitors in bulk water and in the $\mathrm{M}^{\text {pro }}$ binding site. The red and blue structures represent the lowest free energy conformational states adopted by the inhibitors in bulk solution and in the protein binding site, respectively.

The conformational free energy $\left(\Delta \Delta \mathrm{G}_{\text {conf }}\right)$ of the N3 and $\alpha$-ketoamide inhibitors upon binding to the $\mathrm{M}^{\text {pro }}$ is predicted to be $5.4 \pm$ $0.6 \mathrm{kcal} \mathrm{mol}^{-1}$ and $2.9 \pm 0.6 \mathrm{kcal} \mathrm{mol}^{-1}$, respectively (Table 2). This difference in conformational energies can be attributed to the relative size and flexibility of the inhibitors. Between both inhibitors, N3 has the larger size and molecular weight. Large and flexible ligands tend to have higher conformational energies upon binding than small and rigid ligands. ${ }^{87}$ The free energy cost arising from the conformational free energies suggest that there is a greater penalty for $\mathrm{N} 3$ than for $\alpha$-ketoamide binding to the $\mathrm{M}^{\text {pro }}$. In general, these observations provide insights into the strain energy experienced by the peptidomimetic inhibitors in the binding pocket of the $\mathrm{M}^{\mathrm{pro}}$.

Table 2. Conformational Energies of Peptidomimetic Inhibitors upon Binding to the SARS-CoV-2 $\mathrm{M}^{\text {pro }}$.

\begin{tabular}{|c|c|}
\hline Inhibitor & $\Delta \Delta \boldsymbol{G}_{\text {conf }}\left(\mathrm{kcal} \mathrm{mol}^{-1}\right)$ \\
\hline N3 & $5.4 \pm 0.6$ \\
\hline$\alpha$-ketoamide & $2.9 \pm 0.6$ \\
\hline
\end{tabular}

\section{Conclusion}

In this work, we performed rigorous alchemical $\mathrm{ABFE}$ calculations and ONIOM QM/MM calculations to compute the total binding energy of two recently crystallized peptidomimetic inhibitors (N3 and $\alpha$-ketoamide) of SARS-CoV-2 $\mathrm{M}^{\text {pro }}$. The total binding energy consists of both covalent and non-covalent binding energy terms, since these compounds are covalent inhibitors of the $\mathrm{M}^{\text {pro }}$ target. Our results corroborate experimental findings that both $\mathrm{N} 3$ and $\alpha$ ketoamide are potent inhibitors of SARS-CoV-2 $\mathrm{M}^{\text {pro }} .{ }^{33,34}$ We find that the covalent and non-covalent binding free energies of both inhibitors to the $\mathrm{M}^{\text {pro }}$ differ significantly. $\mathrm{N} 3$ enjoys more favourable non-covalent interactions than $\alpha$-ketoamide in the binding site of the $\mathrm{M}^{\mathrm{pro}}$. Hydrogen bonding interactions and dispersion forces are significant to the non-covalent binding energy contributions of the inhibitors to the $\mathrm{M}^{\text {pro }}$ target. The covalent binding free energy of the $\mathrm{M}^{\text {pro }}-\alpha$-ketoamide covalent adduct is greater than the energy 
contribution resulting from the formation of the $\mathrm{M}^{\mathrm{pro}}-\mathrm{N} 3$ covalent adduct. This greatly favours the total binding free energy of the $\alpha$ ketoamide inhibitor to the $\mathrm{M}^{\mathrm{pro}}$. The differences in the covalent and non-covalent binding energies of the inhibitors could be a plausible explanation for their slight differences in antiviral inhibition activity. We also computed the conformational Gibbs energy of the inhibitors upon binding to the $\mathrm{M}^{\mathrm{pro}}$ and found that $\mathrm{N} 3$ experiences a greater free energy penalty upon binding to $\mathrm{M}^{\text {pro }}$ than the $\alpha$-ketoamide inhibitor. Our constant-pH molecular dynamics simulations of the $\mathrm{M}^{\mathrm{pro}}$ indicate that the His41-Cys145 catalytic dyad of the Mpro are uncharged, supporting recent multiscale MD studies. ${ }^{81,82}$ Overall, our results provide insight into the various free energy contributions that drive the binding processes of two potent covalent inhibitors of SARS-CoV- $2 \mathrm{M}^{\text {pro }}$. This information could prove useful in the rational design and assessment of new inhibitors as potential drug leads against the emerging coronavirus disease and future infectious disease outbreaks.

\section{ASSOCIATED CONTENT}

Supporting Information. Details of molecular dynamics simulations and parameters, constant-pH MD simulations and parameters, absolute binding free energy simulations and breakdown of binding free energy components. The molecular topology and input files for the binding free energy calculations are also provided.

\section{AUTHOR INFORMATION}

\section{Corresponding Author}

*E-mail: esaw83@mun.ca; aabusaleh@mun.ca

Phone: +1 (709) 864-6119

\section{Author Contributions}

E.A-W was the primary contributor to writing the manuscript. A.A.A.-S was a secondary contributor to writing the manuscript. All authors have given approval to the final version of the manuscript.

\section{Notes}

The authors declare no competing financial interest.

\section{ACKNOWLEDGMENT}

A.A.A.-S thanks Chen Graduate Scholarship and School of Graduate Studies at Memorial University for funding. We thank Prof. Christopher Rowley for providing valuable feedback on the work. Computational resources were provided by Compute Canada. Additional computational resources were provided by the Center for Health Informatics and Analytics (CHIA) of the Faculty of Medicine at Memorial University of Newfoundland.

\section{ABBREVIATIONS}

$\mathrm{ABFE}$, absolute binding free energy; COVID-19, coronavirus disease 2019; SARS-CoV-2, severe acute respiratory syndrome coronavirus 2 ; $\mathrm{M}^{\text {pro }}$, main protease; $3 \mathrm{CL}^{\text {pro }}, 3 \mathrm{C}$-like protease; $\mathrm{PL}^{\text {pro }}$, papain-like protease; $\mathrm{MD}$, molecular dynamics; $\mathrm{QM} / \mathrm{MM}$, quantum mechanics/molecular mechanics; ONIOM, Our own N-layered Integrated molecular Orbital and molecular Mechanics; CpHMD, constant-pH molecular dynamics; PMF, potential of mean force; RMSD, root-mean square deviation.

\section{REFERENCES}

Guarner, J. Three Emerging Coronaviruses in Two Decades. Am. J. Clin. Pathol. 2020, 153(4), 420-421.

Wu, F.; Zhao, S.; Yu, B.; Chen, Y.-M.; Wang, W.; Song, Z.-G.; Hu, Y.; Tao, Z.-W.; Tian, J.-H.; Pei, Y.-Y.; et al. A New Coronavirus Associated with Human Respiratory Disease in China. Nature 2020, 579 (7798), 265-269.

Tang, J. W.; Tambyah, P. A.; Hui, D. S. C. Emergence of a Novel Coronavirus Causing Respiratory Illness from Wuhan, China. J. Infect. 2020, $80(3), 350-371$

Guan, W.; Ni, Z.; Hu, Y.; Liang, W.; Ou, C.; He, J.; Liu, L.; Shan, H.; Lei, C.; Hui, D. S. C.; et al. Clinical Characteristics of Coronavirus Disease 2019 in China. N. Engl.J. Med. 2020, 382 (18), 1708-1720. Liu, C.; Zhou, Q.; Li, Y.; Garner, L. V.; Watkins, S. P.; Carter, L. J.; Smoot, J.; Gregg, A. C.; Daniels, A. D.; Jervey, S.; et al. Research and Development on Therapeutic Agents and Vaccines for COVID-19 and Related Human Coronavirus Diseases. ACS Cent. Sci. 2020, 6 (3), 315-331.

WHO Coronavirus Disease (COVID-19) Dashboard https://covid19.who.int/ (accessed Nov 12, 2020).

Yang, H.; Yang, M.; Ding, Y.; Liu, Y.; Lou, Z.; Zhou, Z.; Sun, L.; Mo, L.; Ye, S.; Pang, H.; et al. The Crystal Structures of Severe Acute Respiratory Syndrome Virus Main Protease and Its Complex with an Inhibitor. Proc. Natl. Acad. Sci. 2003, 100 (23), 13190-13195.

Wang, H.; He, S.; Deng, W.; Zhang, Y.; Li, G.; Sun, J.; Zhao, W.; Guo, Y.; Yin, Z.; Li, D.; et al. Comprehensive Insights into the Catalytic Mechanism of Middle East Respiratory Syndrome 3C-Like Protease and Severe Acute Respiratory Syndrome 3C-Like Protease. ACS Catal. 2020, 10(10), 5871-5890.

Yin, W.; Mao, C.; Luan, X.; Shen, D.-D.; Shen, Q.; Su, H.; Wang, X.; Zhou, F.; Zhao, W.; Gao, M.; et al. Structural Basis for Inhibition of the RNA-Dependent RNA Polymerase from SARS-CoV-2 by Remdesivir. Science (80-. ). 2020, 368 (6498), 1499-1504

Lan, J.; Ge, J.; Yu, J.; Shan, S.; Zhou, H.; Fan, S.; Zhang, Q.; Shi, X.; Wang, Q.; Zhang, L.; et al. Structure of the SARS-CoV-2 Spike Receptor-Binding Domain Bound to the ACE2 Receptor. Nature 2020, 581 (7807), 215-220.

Otto, H.; Schirmeister, T. Cysteine Proteases and Their Inhibitors. Chem. Rev. 1997, 97(1), 133-172.

Goetz, D. H.; Choe, Y.; Hansell, E.; Chen, Y. T.; McDowell, M.; Jonsson, C. B.; Roush, W. R.; McKerrow, J.; Craik, C. S. Substrate Specificity Profiling and Identification of a New Class of Inhibitor for the Major Protease of the SARS Coronavirus †, $\neq$. Biochemistry 2007, 46(30), 8744-8752.

Pillaiyar, T.; Manickam, M.; Namasivayam, V.; Hayashi, Y.; Jung, S.H. An Overview of Severe Acute Respiratory Syndrome-Coronavirus (SARS-CoV) 3CL Protease Inhibitors: Peptidomimetics and Small Molecule Chemotherapy. J. Med. Chem. 2016, 59 (14), 6595-6628. Jin, Z.; Zhao, Y.; Sun, Y.; Zhang, B.; Wang, H.; Wu, Y.; Zhu, Y.; Zhu, C.; Hu, T.; Du, X.; et al. Structural Basis for the Inhibition of SARSCoV-2 Main Protease by Antineoplastic Drug Carmofur. Nat. Struct. Mol. Biol. 2020, 27(6), 529-532.

Snijder, E. J.; Decroly, E.; Ziebuhr, J. The Nonstructural Proteins Directing Coronavirus RNA Synthesis and Processing. Adv Virus Res 2016, 59-126.

Huynh, T.; Wang, H.; Luan, B. In Silico Exploration of the Molecular Mechanism of Clinically Oriented Drugs for Possibly Inhibiting SARS-CoV-2's Main Protease. J. Phys. Chem. Lett. 2020, 11 (11), 4413-4420.

Parks, J. M.; Smith, J. C. How to Discover Antiviral Drugs Quickly. $N$ Engl. J. Med. 2020, 382 (23), 2261-2264.

Draft landscape of COVID-19 candidate vaccines https://www.who.int/publications/m/item/draft-landscape-ofcovid-19-candidate-vaccines (accessed Nov 12, 2020).

Shaffer, L. 15 Drugs Being Tested to Treat COVID-19 and How They Would Work. Nat.Med. 2020.

Brogi, S.; Ramalho, T. C.; Kuca, K.; Medina-Franco, J. L.; Valko, M Editorial: In Silico Methods for Drug Design and Discovery. Front. Chem. 2020, 8.

Dai, W.; Zhang, B.; Jiang, X.-M.; Su, H.; Li, J.; Zhao, Y.; Xie, X.; Jin, Z.; Peng, J.; Liu, F.; et al. Structure-Based Design of Antiviral Drug Candidates Targeting the SARS-CoV-2 Main Protease. Science (80).2020, 368 (6497), 1331-1335

Zhang, L.; Lin, D.; Kusov, Y.; Nian, Y.; Ma, Q.; Wang, J.; Von Brunn, 
A.; Leyssen, P.; Lanko, K.; Neyts, J.; et al. $\alpha$-Ketoamides as BroadSpectrum Inhibitors of Coronavirus and Enterovirus Replication: Structure-Based Design, Synthesis, and Activity Assessment. J. Med. Chem. 2020, 63(9), 4562-4578.

(23) Wang, J. Fast Identification of Possible Drug Treatment of Coronavirus Disease-19 (COVID-19) through Computational Drug Repurposing Study. J. Chem. Inf. Model. 2020, 60 (6), 3277-3286.

(24) Panda, P. K.; Arul, M. N.; Patel, P.; Verma, S. K.; Luo, W.; Rubahn, H.G.; Mishra, Y. K.; Suar, M.; Ahuja, R. Structure-Based Drug Designing and Immunoinformatics Approach for SARS-CoV-2. Sci. Adv. 2020, 6(28), eabb8097.

(25) Nutho, B.; Mahalapbutr, P.; Hengphasatporn, K.; Pattaranggoon, N. C.; Simanon, N.; Shigeta, Y.; Hannongbua, S.; Rungrotmongkol, T. Why Are Lopinavir and Ritonavir Effective against the Newly Emerged Coronavirus 2019? Atomistic Insights into the Inhibitory Mechanisms. Biochemistry 2020, 59(18), 1769-1779.

(26) Kumar, S.; Sharma, P. P.; Shankar, U.; Kumar, D.; Joshi, S. K.; Pena, L.; Durvasula, R.; Kumar, A.; Kempaiah, P.; Poonam; et al. Discovery of New Hydroxyethylamine Analogs against 3CL pro Protein Target of SARS-CoV-2: Molecular Docking, Molecular Dynamics Simulation, and Structure-Activity Relationship Studies. J. Chem. Inf. Model. 2020, acs.jcim.0c00326.

(27) Sang, P.; Tian, S.-H.; Meng, Z.-H.; Yang, L.-Q. Anti-HIV Drug Repurposing against SARS-CoV-2. RSC Adv. 2020, 10 (27), 1577515783.

(28) Ngo, S. T.; Quynh Anh Pham, N.; Thi Le, L.; Pham, D.-H.; Vu, V. V. Computational Determination of Potential Inhibitors of SARS-CoV2 Main Protease. J. Chem. Inf. Model. 2020, acs.jcim.0c00491.

(29) Havranek, B.; Islam, S. M. An in Silico Approach for Identification of Novel Inhibitors as Potential Therapeutics Targeting COVID-19 Main Protease. J. Biomol. Struct. Dyn. 2020, 1-12.

(30) Tahir ul Qamar, M.; Alqahtani, S. M.; Alamri, M. A.; Chen, L.-L. Structural Basis of SARS-CoV-2 3CLpro and Anti-COVID-19 Drug Discovery from Medicinal Plants. J. Pharm. Anal. 2020, 10 (4), 313 319.

(31) Gutierrez-Villagomez, J. M.; Campos-García, T.; Molina-Torres, J.; López, M. G.; Vázquez-Martínez, J. Alkamides and Piperamides as Potential Antivirals against the Severe Acute Respiratory Syndrome Coronavirus 2 (SARS-CoV-2). J. Phys. Chem. Lett. 2020, 11 (19), 8008-8016.

(32) Ma, C.; Sacco, M. D.; Hurst, B.; Townsend, J. A.; Hu, Y.; Szeto, T.; Zhang, X.; Tarbet, B.; Marty, M. T.; Chen, Y.; et al. Boceprevir, GC376, and Calpain Inhibitors II, XII Inhibit SARS-CoV-2 Viral Replication by Targeting the Viral Main Protease. Cell Res. 2020, 30 (8), 678-692.

(33) Jin, Z.; Du, X.; Xu, Y.; Deng, Y.; Liu, M.; Zhao, Y.; Zhang, B.; Li, X.; Zhang, L.; Peng, C.; et al. Structure of Mpro from SARS-CoV-2 and Discovery of Its Inhibitors. Nature 2020, 582 (7811), 289-293.

(34) Zhang, L.; Lin, D.; Sun, X.; Curth, U.; Drosten, C.; Sauerhering, L.; Becker, S.; Rox, K.; Hilgenfeld, R. Crystal Structure of SARS-CoV-2 Main Protease Provides a Basis for Design of Improved $\alpha$-Ketoamide Inhibitors. Science (80-. ). 2020, 368 (6489), 409-412.

(35) Dai, W.; Zhang, B.; Jiang, X.-M.; Su, H.; Li, J.; Zhao, Y.; Xie, X.; Jin, Z.; Peng, J.; Liu, F.; et al. Structure-Based Design of Antiviral Drug Candidates Targeting the SARS-CoV-2 Main Protease. Science (80).2020, 368 (6497), 1331-1335.

(36) Yoshino, R.; Yasuo, N.; Sekijima, M. Identification of Key Interactions between SARS-CoV-2 Main Protease and Inhibitor Drug Candidates. Sci. Rep. 2020, $10(1), 1-8$.

(37) Hatada, R.; Okuwaki, K.; Mochizuki, Y.; Handa, Y.; Fukuzawa, K.; Komeiji, Y.; Okiyama, Y.; Tanaka, S. Fragment Molecular Orbital Based Interaction Analyses on COVID-19 Main Protease - Inhibitor N3 Complex (PDB ID: 6LU7). J. Chem. Inf. Model. 2020, 60 (7), 3593-3602.

(38) Liang, J.; Pitsillou, E.; Karagiannis, C.; Darmawan, K. K.; Ng, K.; Hung, A.; Karagiannis, T. C. Interaction of the Prototypical $\alpha$ Ketoamide Inhibitor with the SARS-CoV-2 Main Protease Active Site in Silico: Molecular Dynamic Simulations Highlight the Stability of the Ligand-Protein Complex. Comput. Biol. Chem. 2020, 87(April), 107292.

(39) Griffin, J. W. D. SARS-CoV and SARS-CoV-2 Main Protease Residue Interaction Networks Change When Bound to Inhibitor N3. J. Struct. Biol. 2020, 211 (3), 107575.
(40) Banerjee, S. An Insight into the Interaction Between $\alpha$-KetoamideBased Inhibitor and Coronavirus Main Protease: A Detailed in Silico Study. 2020, No. 2, 1-43.

(41) Pavlova, A.; Lynch, D. L.; Daidone, I.; Zanetti-polzi, L.; Dean, M.; Chipot, C.; Kneller, D. W.; Kovalevsky, A.; Coates, L.; Andrei, A.; et al. Inhibitor Binding Influences the Protonation States of Histidines in SARS-CoV-2 Main Protease. 2020, 1-38.

(42) Mittal, L.; Kumari, A.; Srivastava, M.; Singh, M.; Asthana, S. Identification of Potential Molecules against COVID-19 Main Protease through Structure-Guided Virtual Screening Approach. $J$. Biomol. Struct. Dyn. 2020, o(0), 1-19.

(43) Abu-Saleh, A. A.-A. A.; Awad, I. E.; Yadav, A.; Poirier, R. A. Discovery of Potent Inhibitors for SARS-CoV-2's Main Protease by LigandBased/Structure-Based Virtual Screening, MD Simulations, and Binding Energy Calculations. Phys. Chem. Chem. Phys. 2020, 22 (40), 23099-23106.

(44) Frecer, V.; Miertus, S. Antiviral Agents against COVID-19: StructureBased Design of Specific Peptidomimetic Inhibitors of SARS-CoV-2 Main Protease. RSC Adv. 2020, 10 (66), 40244-40263.

(45) Cournia, Z.; Allen, B. K.; Beuming, T.; Pearlman, D. A.; Radak, B. K.; Sherman, W. Rigorous Free Energy Simulations in Virtual Screening. J. Chem. Inf. Model. 2020, 60 (9), 4153-4169.

(46) Lin, Y. L.; Roux, B. Computational Analysis of the Binding Specificity of Gleevec to Abl, c-Kit, Lck, and c-Src Tyrosine Kinases. J. Am. Chem. Soc. 2013, 135(39), 14741-14753.

(47) Lin, Y.-L.; Meng, Y.; Jiang, W.; Roux, B. Explaining Why Gleevec Is a Specific and Potent Inhibitor of Abl Kinase. Proc. Natl. Acad. Sci. U. S. A. 2013, $110(5), 1664-1669$.

(48) Lin, Y. L.; Meng, Y.; Huang, L.; Roux, B. Computational Study of Gleevec and G6G Reveals Molecular Determinants of Kinase Inhibitor Selectivity. J. Am. Chem. Soc. 2014, 136 (42), 1475314762 .

(49) Aldeghi, M.; Heifetz, A.; Bodkin, M. J.; Knapp, S.; Biggin, P. C. Accurate Calculation of the Absolute Free Energy of Binding for Drug Molecules. Chem. Sci. 2016, 7(1), 207-218.

(50) Aldeghi, M.; Heifetz, A.; Bodkin, M. J.; Knapp, S.; Biggin, P. C. Predictions of Ligand Selectivity from Absolute Binding Free Energy Calculations. J. Am. Chem. Soc. 2017, 139(2), 946-957.

(51) Awoonor-Williams, E.; Rowley, C. Calculating the Full Free Energy Profile for Covalent Modification of a Druggable Cysteine in Bruton's Tyrosine Kinase. 2020. ChemRxiv Preprint. https://doi.org/10.26434/chemrxiv.13132814.v1

(52) Awoonor-Williams, E.; Walsh, A. G.; Rowley, C. N. Modeling Covalent-Modifier Drugs. Biochim. Biophys. Acta - Proteins Proteomics 2017, 1865 (11), 1664-1675.

(53) Awoonor-Williams, E.; Isley, W. C.; Dale, S. G.; Johnson, E. R.; Yu, H.; Becke, A. D.; Roux, B.; Rowley, C. N. Quantum Chemical Methods for Modeling Covalent Modification of Biological Thiols. J. Comput. Chem. 2019, 5609, 45103.

(54) Chung, L. W.; Sameera, W. M. C.; Ramozzi, R.; Page, A. J.; Hatanaka, M.; Petrova, G. P.; Harris, T. V.; Li, X.; Ke, Z.; Liu, F.; et al. The ONIOM Method and Its Applications. Chem. Rev. 2015, 115 (12), 5678-5796.

(55) Best, R. B.; Zhu, X.; Shim, J.; Lopes, P. E. M.; Mittal, J.; Feig, M.; MacKerell, A. D. Optimization of the Additive CHARMM All-Atom Protein Force Field Targeting Improved Sampling of the Backbone $\phi$, $\psi$ and Side-Chain $\chi 1$ and $\chi 2$ Dihedral Angles. J. Chem. Theory Comput. 2012, $8(9)$, 3257-3273.

(56) Vanommeslaeghe, K.; Hatcher, E.; Acharya, C.; Kundu, S.; Zhong, S.; Shim, J.; Darian, E.; Guvench, O.; Lopes, P.; Vorobyov, I.; et al. CHARMM General Force Field: A Force Field for Drug-like Molecules Compatible with the CHARMM All-Atom Additive Biological Force Fields. J. Comput. Chem. 2010, 31 (4), 671-690.

(57) Jorgensen, W. L.; Chandrasekhar, J.; Madura, J. D.; Impey, R. W.; Klein, M. L. Comparison of Simple Potential Functions for Simulating Liquid Water. J. Chem. Phys. 1983, 79 (2), 926.

(58) Phillips, J. C.; Braun, R.; Wang, W.; Gumbart, J.; Tajkhorshid, E.; Villa, E.; Chipot, C.; Skeel, R. D.; Kalé, L.; Schulten, K. Scalable Molecular Dynamics with NAMD. J. Comput. Chem. 2005, 26(16), 1781-1802. Darden, T.; York, D.; Pedersen, L. Particle Mesh Ewald: An N Log(N) Method for Ewald Sums in Large Systems. J. Chem. Phys. 1993, 98 (12), 10089

(60) Essmann, U.; Perera, L.; Berkowitz, M. L.; Darden, T.; Lee, H.; 
Pedersen, L. G. A Smooth Particle Mesh Ewald Method. J. Chem. Phys. 1995, 103 (19), 8577-8593.

(61) Ryckaert, J.-P.; Ciccotti, G.; Berendsen, H. J. . Numerical Integration of the Cartesian Equations of Motion of a System with Constraints: Molecular Dynamics of n-Alkanes. J. Comput. Phys. 1977, 23 (3), 327-341.

(62) Henderson, J. A.; Verma, N.; Harris, R. C.; Liu, R.; Shen, J. Assessment of Proton-Coupled Conformational Dynamics of SARS and MERS Coronavirus Papain-like Proteases: Implication for Designing BroadSpectrum Antiviral Inhibitors. J. Chem. Phys. 2020, 153(11), 115101.

(63) Radak, B. K.; Chipot, C.; Suh, D.; Jo, S.; Jiang, W.; Phillips, J. C.; Schulten, K.; Roux, B. Constant-PH Molecular Dynamics Simulations for Large Biomolecular Systems. J. Chem. Theory Comput. 2017, 13 (12), 5933-5944.

(64) Awoonor-Williams, E.; Rowley, C. N. Evaluation of Methods for the Calculation of the PKa of Cysteine Residues in Proteins. J. Chem. Theory Comput. 2016, 12 (9), 4662-4673.

(65) Awoonor-Williams, E.; Rowley, C. N. How Reactive Are Druggable Cysteines in Protein Kinases? J. Chem. Inf. Model. 2018, 58 (9), 1935-1946.

(66) Awoonor-Williams, E.; Rowley, C. N. The Hydration Structure of Methylthiolate from QM/MM Molecular Dynamics. J. Chem. Phys. 2018, 149(4), 045103.

(67) Abraham, M. J.; Murtola, T.; Schulz, R.; Páll, S.; Smith, J. C.; Hess, B.; Lindahl, E. GROMACS: High Performance Molecular Simulations through Multi-Level Parallelism from Laptops to Supercomputers. SoftwareX2015, 1-2, 19-25.

(68) Aliev, A. E.; Kulke, M.; Khaneja, H. S.; Chudasama, V.; Sheppard, T. D.; Lanigan, R. M. Motional Timescale Predictions by Molecular Dynamics Simulations: Case Study Using Proline and Hydroxyproline Sidechain Dynamics. Proteins Struct. Funct. Bioinforma. 2014, 82 (2), 195-215.

(69) Wang, J.; Wolf, R. M.; Caldwell, J. W.; Kollman, P. A.; Case, D. A. Development and Testing of a General Amber Force Field. 2004, 56531 .

(70) Goga, N.; Rzepiela, A. J.; de Vries, A. H.; Marrink, S. J.; Berendsen, H. J. C. Efficient Algorithms for Langevin and DPD Dynamics. J. Chem. Theory Comput. 2012, 8(10), 3637-3649.

(71) Berendsen, H. J. C.; Postma, J. P. M.; van Gunsteren, W. F.; DiNola A.; Haak, J. R. Molecular Dynamics with Coupling to an External Bath. J. Chem. Phys. 1984, 81 (8), 3684-3690.

(72) Parrinello, M.; Rahman, A. Polymorphic Transitions in Single Crystals: A New Molecular Dynamics Method. J. Appl. Phys. 1981, 52 (12), 7182-7190.

(73) Klimovich, P. V.; Shirts, M. R.; Mobley, D. L. Guidelines for the Analysis of Free Energy Calculations. J. Comput. Aided. Mol. Des.
2015, No. January, 397-411.

Shirts, M. R.; Chodera, J. D. Statistically Optimal Analysis of Samples from Multiple Equilibrium States. J. Chem. Phys. 2008, 129 (12), 124105 .

(75) Boresch, S.; Tettinger, F.; Leitgeb, M.; Karplus, M. Absolute Binding Free Energies: A Quantitative Approach for Their Calculation. J. Phys. Chem. B 2003, 107(35), 9535-9551.

(76) Grossfield, A. WHAM: The Weighted Histogram Analysis Method, Version 2.0.9. Rochester University, Rochester, NY, 2013.

(77) Frisch, M. J.; Trucks, G. W.; Schlegel, H. B.; Scuseria, G. E.; Robb, M. A.; Cheeseman, J. R.; Scalmani, G.; Barone, V.; Petersson, G. A.; Nakatsuji, H.; Li, X.; Caricato, M.; Marenich, A. V.; Bloino, J.; Janesko, B. G.; Gomperts, R.; Mennucci, B.; Hratch, D. J. Gaussian 16, Revision C.03. Gaussian Inc., Wallingford CT, 2016.

(78) Mardirossian, N.; Head-Gordon, M. How Accurate Are the Minnesota Density Functionals for Noncovalent Interactions, Isomerization Energies, Thermochemistry, and Barrier Heights Involving Molecules Composed of Main-Group Elements? J. Chem. Theory Comput. 2016, 12 (9), 4303-4325.

(79) Fukui, K. The Path of Chemical Reactions - the IRC Approach. Acc. Chem. Res. 1981, 14 (12), 363-368.

(80) Hratchian, H. P.; Schlegel, H. B. Using Hessian Updating to Increase the Efficiency of a Hessian Based Predictor-Corrector Reaction Path Following Method. J. Chem. Theory Comput. 2005, 1 (1), 61-69.

(81) Świderek, K.; Moliner, V. Revealing the Molecular Mechanisms of Proteolysis of SARS-CoV-2 M pro by QM/MM Computational Methods. Chem. Sci. 2020, 11 (39), 10626-10630.

(82) Ramos-Guzmán, C. A.; Ruiz-Pernía, J. J.; Tunón, I. Unraveling the SARS-CoV-2 Main Protease Mechanism Using Multiscale Methods. ACS Catal. 2020, 10 (21), 12544-12554.

(83) Huang, C.; Wei, P.; Fan, K.; Liu, Y.; Lai, L. 3C-like Proteinase from SARS Coronavirus Catalyzes Substrate Hydrolysis by a General Base Mechanism. Biochemistry 2004, 43 (15), 4568-4574.

(84) Morse, J. S.; Lalonde, T.; Xu, S.; Liu, W. R. Learning from the Past: Possible Urgent Prevention and Treatment Options for Severe Acute Respiratory Infections Caused by 2019-nCoV. ChemBioChem 2020, $21(5), 730-738$.

(85) Yang, H.; Xie, W.; Xue, X.; Yang, K.; Ma, J.; Liang, W.; Zhao, Q.; Zhou, Z.; Pei, D.; Ziebuhr, J.; et al. Design of Wide-Spectrum Inhibitors Targeting Coronavirus Main Proteases. PLoS Biol. 2005, 3 (10).

(86) Woo, H. J.; Roux, B. Calculation of Absolute Protein-Ligand Binding Free Energy from Computer Simulations. Proc. Natl. Acad. Sci. U. S A. 2005, 102 (19), 6825-6830.

(87) Gao, C.; Park, M.-S.; Stern, H. A. Accounting for Ligand Conformational Restriction in Calculations of Protein-Ligand Binding Affinities. Biophys. J. 2010, 98 (5), 901-910. 